\title{
Capsule Commentary on Katz et al., Implementing Smoking Cessation Guidelines for Hospitalized Veterans: Effects on Nurse Attitudes and Performance
}

\author{
Jennifer M. Gierisch, $P h D M P H^{1,2}$ and Laura J. Fish, $P h D^{3}$ \\ ${ }^{1}$ Center for Health Services Research in Primary Care, Durham Veterans Affairs Medical Center, Durham, USA; ${ }^{2}$ Department of Medicine, \\ Duke University Medical Center, Durham, USA; ${ }^{3}$ Department of Community and Family Medicine, Duke University Medical Center, Durham, \\ NC, USA.
}

J Gen Intern Med 28(11): 1493

DOI: $10.1007 /$ s11606-013-2503-4

(C) Society of General Internal Medicine 2013

$\mathrm{P}$ revious smoking cessation interventions for hospitalized patients have shown only modest effects; ${ }^{1}$ understanding the process of delivering such interventions to inpatients is important. Katz ${ }^{2}$ takes an important next step using mixed methods to triangulate implementation barriers and facilitators of a multi-level nurse-led smoking cessation intervention for hospitalized smokers. While the intervention improved guideline concordant care, qualitative findings highlight some key implementation barriers such as time constraints, difficulty in placing pharmacotherapy "quick orders," and nurses' attitudes towards delivering cessation advice and beliefs about patient resistance to quitting. These factors may have attenuated intervention effects and likely would not have been captured by quantitative methods alone. These findings underscore the importance of qualitative methods in intervention research; they can provide insight into aspects of the project not amenable to quantitative methods. ${ }^{3}$

As healthcare systems shift from one-on-one providerpatient care to team-based care, it is useful to consider how other members of care teams may be accessed to provide patient preventive care. Staff nurses are the largest group of inpatient providers; enabling nurses with tools and additional training appears to be a viable option to increase reach of in-patient cessation interventions. ${ }^{4}$

Conflict of Interest: The authors declare that they have no conflicts of interest.

Corresponding Author: Laura J. Fish, PhD; Department of Community and Family Medicine, Duke University Medical Center, Durham, NC, USA (e-mail: Laura.Fish@Duke.edu).

\section{REFERENCES}

1. Rigotti NA, Clair C, Munafò MR, Stead LF. Interventions for smoking cessation in hospitalized patients. Cochrane Database Syst Rev. 2012;(5): Art. No.: CD001837.

2. Katz D, Holman J, Johnson S, Hillis SL, Ono S, Stewart K, Paez M, Fu S, Grant K, Buchanan L, Prochazka A, Battaglia C, Titler M, Vander Weg MW. Implementing smoking cessation guidelines for hospitalized veterans: Effects on nurse attitudes and performance. J Gen Intern Med. 2013. doi:10.1007/s11606-013-2464-7.

3. Peterson JC, Czajkowski S, Charlson ME, Link AR, Wells MT, Isen AM, Mancuso CA, Allegrante JP, Boutin-Foster C, Ogedegbe G, Jobe JB. Translating basic behavioral and social science research to clinical application: the EVOLVE mixed methods approach. J Consult Clin Psychol. 2013;81(2):217-230.

4. Rice VH, Stead LF. Nursing interventions for smoking cessation. Cochrane Database Syst Rev. 2008(1):Art. No.: CD001188.

Published online June 6, 2013 